\title{
Castillo, Gerardo. Local Experiences of Mining in Peru: Social and Spatial Transformations in the Andes. Nueva York: Routledge, 2020, 130 pp. (ISBN 978-0-367-25886-3)
}

En la última década se ha desarrollado una abundante literatura sobre las transformaciones sociales en localidades con minería a gran escala en los Andes. Estos estudios han propuesto, desde distintas disciplinas y enfoques sociales, interesantes debates sobre los cambios institucionales, políticos, económicos o culturales que la minería corporativa contemporánea ha impulsado en localidades andinas. En su libro Local Experiences of Mining in Peru: Social and Spatial Transformations in the Andes, Castillo dialoga, debate y enriquece varios de dichos debates por lo que el libro representa una importante contribución.

El libro analiza los procesos de cambio en los caseríos ubicados alrededor del proyecto minero La Granja, en el departamento de Cajamarca, en los Andes del norte del Perú, donde de manera sucesiva tres empresas mineras, dos de ellas entre las más grandes del sector, han buscado sin éxito desarrollar proyectos mineros para explotar uno de los depósitos de cobre más grandes del mundo. Para ello, el autor nos relata los distintos cambios experimentados por las familias locales, y por las localidades mismas como espacios sociales, desde antes de la llegada de la minería hasta la última experiencia minera con la empresa Río Tinto.

El libro presenta y desarrolla el concepto de Lefebvre de producción del espacio, enfocándose en la producción del espacio vivido, es decir, la producción social desde abajo a partir de la cual las experiencias locales pueden constituirse en ejes analíticos para entender tanto los cambios sociales como la transformación misma de los lugares. Es por ello que el autor nos invita a seguir las experiencias de las familias durante décadas para, a través de estas, entender las transformaciones sociales como procesos históricos, en particular a partir de la llegada de la minería a gran escala.

Las historias locales que constituyen el centro de la evidencia analizada fueron recogidas por medio de instrumentos etnográfico en sucesivos trabajos de campo y son presentadas a través del texto por medio de testimonios y mapas donde se grafica los flujos demográficos y transformaciones territoriales. El apego a la narrativa histórica, expresada muchas veces de forma testimonial y geográfica, imprime al texto una identidad especial con relación a la mayoría de estudios sociales sobre minería, y seguramente tiene que ver con la propia experiencia académica del autor. 
En términos generales, el libro argumenta que la minería moldea y acelera procesos de cambio en cuatro dimensiones interrelacionadas: acceso a la tierra, producción, movilidad y representación espacial. Luego de los capítulos introductorios, donde se expone el marco teórico y se contextualiza tanto histórica como geográficamente al espacio de estudio, el autor emprende el análisis de las transformaciones sociales en cada una de las dimensiones planteadas. Cada dimensión es trabajada en un capítulo distinto a partir de un análisis histórico. Así, volvemos a las historias locales una y otra vez, pero siguiendo enfoques y objetivos analíticos distintos. Como en una buena novela, los fragmentos de historia presentados en cada capítulo buscan ser integrados en una sola línea narrativa que nos da cuenta de la producción y reproducción de los lugares como espacios sociales desde la experiencia local.

El libro nos presenta un conjunto de temas de los cuales quisiera subrayar algunos. En el capítulo Acceso, se busca entender la relación entre acceso a la tierra e identidad territorial. Para ello, el autor se concentra, considero acertadamente, en los procesos de reforma agraria y en el impacto de la minería como puntos centrales en la historia local de la tierra. Así, podemos entender cómo la ausencia de propiedad comunal o el desarrollo de un mercado de tierras con repercusiones supralocales, influyen en la identidad territorial de las familias. El capítulo Producción nos muestra cómo la presencia minera impulsó la creciente diversificación en la economía doméstica de las familias locales en el contexto de lo que la literatura actual identifica como nueva ruralidad. También en este capítulo el libro aborda un tema de suma importancia: el impacto del empleo minero. Aquí el autor argumenta que la política corporativa de Río Tinto, que canaliza el acceso al empleo por medio las rondas campesinas, genera procesos de revitalización en dichas organizaciones locales. El capítulo Movilidad nos muestra los patrones de migración permanente y temporal, así como la diáspora provocada por la minería para explicarnos fenómenos sociales presentes en la zona como la movilidad constante y la doble residencia.

El capítulo que considero más acabado es Representaciones, donde el autor analiza la manera en que distintos grupos perciben su espacio social en el presente, pasado y futuro. Vemos cómo sujetos, desde posiciones distintas idealizan el pasado, interpretan el presente y expresan sus expectativas hacia el futuro en relación con las distintas transformaciones que han experimentado. Así, las experiencias locales narradas en capítulos precedentes constituyen la base para la construcción de representaciones sociales de los caseríos: representaciones de espacios dinámicos con características y fronteras flexibles. La minería repercute 
en las sociedades locales y la manera en que estas representan su espacio de adscripción. El resultado: miradas ambiguas y a veces contradictorias sobre cómo la minería transforma dichos espacios locales.

Otro punto sobresaliente del texto es la inclusión, transversal a todo el texto, de las diferencias de género. Se aprecia en el autor la voluntad de visibilizar las experiencias y visiones de las mujeres, quienes muchas veces se ven relegadas en sociedades donde el espacio público es marcadamente masculino, como en este caso. Este análisis en específico considero es una contribución especial del libro a la literatura sobre minería y género.

En resumen, Local Experiences of Mining in Peru: Social and Spatial Transformations in the Andes nos propone en su estructura y contenido un modelo para armar donde las piezas, unas más acabadas que otras, son los capítulos que se abren a temáticas diversas y que finalmente terminan confluyendo en un texto acabado de alta calidad académica.

Gerardo Damonte Valencia

(iD) https://orcid.org/0000-0002-0529-2124 Pontificia Universidad Católica del Perú gdamonte@pucp.pe

\section{Resumen}

El libro Local Experiences of Mining in Peru: Social and Spatial Transformations in the Andes nos muestra cómo las experiencias y representaciones van construyendo y reconstruyendo los sitios mineros. Para ello, el autor nos incorpora a los debates sobre los cambios institucionales, políticos, económicos o culturales que la minería corporativa contemporánea ha impulsado en localidades andinas. Palabras clave: minería, experiencias locales, cambios Institucionales, transformaciones espaciales. 